\title{
KONTROL DIRI DAN PERILAKU MEROKOK PADA SISWA SMA
}

\author{
Indra Dwi Setiawan ${ }^{1}$, Octa Reni Setiawati², Sri Maria Puji Lestari ${ }^{3}$ \\ ${ }^{1}$ Program Studi Kedokteran Fakultas Kedokteran Universitas Malahayati, email: \\ indradwisetiawan65@gmail.com \\ 2Program Studi Psikologi Fakultas Kedokteran Universitas Malahayati, email: ores.survive@gmail.com \\ 3Program Studi Kedokteran Fakultas Kedokteran Universitas Malahayati, email: srimaria13pl@yahoo.com
}

\section{ABSTRACT: SELF CONTROL AND SMOKING BEHAVIOR IN HIGH SCHOOL STUDENT}

Smoking behavior appears a lot among adolescents. Smoking behavior is a form of juvenile delinquency related to self-control abilities. This study aims to determine the relationship between self-control and smoking behavior in high school students. The study was conducted on 205 students of SMA Negeri 1 Trimurjo, Central Lampung Regency. The research data were obtained through self-control questionnaires and smoking behavior. Data analysis used Pearson correlation test. The results showed that high school students had moderate self-control and smoking behavior. There is a significant relationship between selfcontrol and smoking behavior in high school students, with low correlation strength and negative correlation direction, which means the higher self-control, the lower one's smoking behavior. The results of this study can be a reference for the school in developing self-control intervention programs to reduce smoking behavior among high school students.

\section{Keywords: Self-Control, Smoking Behavior, High School Students}

Perilaku merokok banyak muncul di kalangan remaja. Perilaku merokok merupakan bentuk kenakalan remaja yang berhubungan dengan kemampuan pengendalian diri. Penelitian ini bertujuan untuk mengetahui hubungan kontrol diri dengan perilaku merokok pada siswa SMA. Penelitian dilakukan terhadap 205 siswa SMA Negeri 1 Trimurjo Kabupaten Lampung Tengah. Data penelitian diperoleh melalui kuesioner kontrol diri dan perilaku merokok. Analisis data menggunakan uji korelasi Pearson. Hasil penelitian menunjukkan siswa SMA memiliki control diri dan perilaku merokok tingkat sedang. Terdapat hubungan bermakna antara kontrol diri dan perilaku merokok pada siswa SMA, dengan kekuatan korelasi rendah dan arah korelasi negatif yaitu semakin tinggi kontrol diri maka semakin rendah perilaku merokok seseorang. Hasil penelitian ini dapat menjadi acuan bagi pihak sekolah dalam mengembangkan program intervensi control diri untuk. mengurangi perilaku merokok siswa SMA.

\section{Kata Kunci :Kontrol Diri, Perilaku Merokok, Siswa SMA}

\section{PENDAHULUAN}

Indonesia adalah salah satu konsumen rokok terbesar di dunia menurut laporan World Health Organization (WHO) tahun 2011 dengan prevalensi merokok pada laki-laki $46,8 \%$ dan perempuan $3,1 \%$ berusia 10 tahun ke atas. Jumlah perokok paling besar pada kalangan menengah kebawah dengan persentase sebanyak $40 \%$ dari jumlah perokok di Indonesia yang berjumlah 62,8 juta (Faridah, 2015.). Hasil penelitian yang dilakukan sebelumnya oleh Amalia (2018), di dapatkan 2772 siswa $(39,05 \%)$ menunjukkan perilaku merokok tingkat rendah, 3566 siswa $(50,23 \%)$ berperilaku merokok tingkat sedang, serta 761 siswa $(10,72 \%)$ berperilaku merokok tingkat tinggi. Menurut data Kemenkes RI tahun 2011 prevalensi merokok di Provinsi Lampung adalah salah satu yang terbesar dengan presentase 38\%. Prevalensi perokok di kota ini lebih tinggi pada laki-laki 


\section{KONTROL DIRI DAN PERILAKU MEROKOK PADA SISWA SMA}

dengan persentase sebesar 65,9\%, dan perempuan 4,2\%. Prevalensi merokok paling tinggi pada penduduk yang tinggal dipedesaan, dikarenakan rendahnya tingkat pendidikan seperti tidak tamat SD, pekerjaan informal sebagai petani/ nelayan/ buruh, dan status ekonomi rendah (Hernawily \& Amperaningsih, 2015). Data dari Riset Kesehatan Dasar tahun 2010 menunjukkan bahwa tingginya prevalensi merokok pada remaja dengan rentang usia 1519 tahun, yaitu 43,3\% (Wijayanti, 2017).

Masa remaja adalah masa peralihan perkembangan dari masa anak-anak menuju ke masa dewasa, perkembangan dapat berupa perkembangan fisik, mental, sosial, dan emosional. Pada masa peralihan ini juga terjadi pencarian jati diri yang berlangsung pada usia 13 sampai 18 tahun, yaitu pada masa anak masih duduk di bangku sekolah menengah dan merupakan periode remaja awal (Ali \& Asrori, 2014). Perilaku merokok di kalangan remaja sekarang bukanlah hal baru lagi.Tidak jarang kita menemukan remaja yang masih mengenakan seragam sekolahnya, (baik SMP maupun SMA) merokok bersama temantemanyaataupun sendiri, baik merokok secara terangterangan maupun secara sembunyi sembunyi (Isa, Lestari, \& Afa, 2017).

Erikson mengungkapkan remaja
mulai merokok berkaitan dengan adanya
krisis psikososial yang dialami pada masa
perkembangannya yaitu masa ketika mereka

sedang mencari jati dirinya. Dalam masa remaja ini, sering dilukiskan sebagai masa badai dan topan karena ketidaksesuaian antara perkembangan psikis dan sosial. Begitu pula pendapat Brigham (dalam Fadly, 2015) bahwa perilaku merokok bagi remaja merupakan perilaku simbolisasi, yaitu simbol dari kematangan, kekuatan, kepemimpinan, dan daya tarik terhadap lawan jenis .

Pada periode remaja awal, perkembangan fisik pada remaja semakin tampak, seperti perubahan pada fungsi alat kelamin, dan juga remaja seringkali sulit untuk menyesuaikan diri dengan perubahanperubahan pada diri mereka, dan membuat mereka akan cenderung meyendiri, merasa tersisihkan, kurang perhatian dari lingkungan sekitar, bahkan mereka akan merasa tidak ada yang peduli , sehingga untuk meyakinkan teman atau lingkungan sekitarnya mereka akan lebih cepat marah dengan cara yang kurang baik dan akan lebih sulit mengontrol diri mereka sendiri (Ali \& Asrori, 2014).

Menurut Goldfield dan Merbaum (dalam Wulaningsih \& Hartini, 2015) kontrol diri merupakan suatu kemampuan untuk membimbing, menyusun, mengarahkan dan mengatur bentuk perilaku yang dapat membawa individu ke arah konsekuensi baik. Kontrol diri yang rendah pada remaja akan memunculkan tindakan yang tidak terkontrol dan mengarah ke perilaku negatif seperti perilaku merokok, hal ini

Indra Dwi Setiawan, Program Studi Kedokteran Fakultas Kedokteran Universitas Malahayati. Email: indradwisetiawan65@gmail.com

Octa Reni Setiawati, Program Studi Psikologi Fakultas Kedokteran Universitas Malahayati. Email: ores.survie@gmail.com

Sri Maria Puji Lestari, Program Studi Kedokteran Fakultas Kedokteran Universitas Malahayati. Email: srimaria13pl@gmail.com 


\section{KONTROL DIRI DAN PERILAKU MEROKOK PADA SISWA SMA}

diakibatkan remaja yang tidak mampu untuk mengarahkan danmengatur perilakunya (Runtukahu, Sinolungan, \& Opod, 2015).

Perilaku merokok berdampak buruk bagi kesehatan, penyakit yang disebabkan oleh rokok antara lain batuk menahun, penyakit paru, infertilitas, gangguan kehamilan, arthrosklerosis, dan penyakit kanker seperti kanker mulut dan paru (Maseda, Suba, \& Wongkar, 2013). Menurut Sadri (dalam Winengan, 2017) bahaya merokok bagi kesehatan di antaranya impotensi, osteoporosis, gangguan kehamilan, serangan jantung koroner, dan gangguan sistem pernapasan

Jika perilaku muncul sejak remaja, bahaya merokok menjadi lebih besar dikarnakan terdapat Nicotiana tubacum yang dapat menyebabkan ketagihan. Ketagihan ini dikenal dengan Tobaco dependency yaitu perilaku penggunaan tembakau yang menetap, penggunaaan secara terus menerus dapat menyebabkan kanker di penyumbatan pembuluh darah yang mengakibatkan kematian(Setyani \& Sodik, 2018). Oleh karna itu merokok merupakan jalur yang sangat berbahaya menuju hilangnya produktivitas dan hilangnya kesehatan (Hernawily \& Amperaningsih, 2015).

Menurut Fadly (2015), perilaku merokok pada remaja disebabkan oleh beberapa faktor, yaitu internal dan eksternal. Faktor eksternal antara lain keluarga, lingkungan sekolah yang tidak menguntungkan dan lingkungan sekitar. Sedangkankan faktor internal antara lain orang tua, teman dan kepribadian. Salah satu karakter kepribadian yang berhubungan dengan perilaku merokok adalah kontrol diri. Hal ini didukung oleh penelitian sebelumnya oleh Fadly (2015), yang menemukan adanya pengaruh kontrol diri terhadap perilaku merokok dengan sumbangan sebesar 69.9\% terhadap perilaku merokok. Pengaruh yang ditemukan bersifat negative, kontrol diri yang rendah berhubungan dengan meningkatnya perilaku merokok pada remaja.

Berdasarkan uruaian di atas maka tujuan dari penelitian ini adalah mengetahui klasifikasi kontrol diri, tingkatan perilaku merokok,dan hubungan kontrol diri dengan perilaku merokok pada siswa SMA.

\section{METODE}

Penelitian ini adalah merupakan penelitian analitik dengan rancangan cross sectional. Sampel penelitian berujumlah 205 siswa SMA Negeri 1 Trimurjo, Kabupaten Lampung Tengah yang diperoleh melalui metode simple random sampling. Penelitian ini menggunakan kuesioner kontrol diri dan perilaku merokok.

Kuesioner kontrol diri dikembangkan berdasarkan teori Baumeister (dalam Permatasari, 2016) yg menggambarkan kontrol diri dalam 3 aspek, yaitu: standar-standar 11

Indra Dwi Setiawan, Program Studi Kedokteran Fakultas Kedokteran Universitas Malahayati. Email: indradwisetiawan65@gmail.com

Octa Reni Setiawati, Program Studi Psikologi Fakultas Kedokteran Universitas Malahayati. Email: ores.survie@gmail.com

Sri Maria Puji Lestari, Program Studi Kedokteran Fakultas Kedokteran Universitas Malahayati. Email: srimaria13pl@gmail.com 
item, pengawasan 9 item, kapasitas untuk berubah 11 item, sehingga total item dalam kuesioner ini berjumlah 31 item. Kuesioner ini sudah melalui uji validitas dan reliabilitas, dengan nilai $r=.361$ dan alpha cronbach .957 . Lebih lanjut untuk kuesioner perilaku merokok dikembangkan berdasarkan penelitian sebelumnya oleh Fadly (2015). Kuesioner ini sudah melalui uji validitas dan rehabilitas, dengan $r=.361$ dan alpha cronbach .935 .

Data yang terkumpul dalam penelitian ini akan dianalisis menggunakan teknik korelasi dengan bantuan software SPSS

HASIL

Tabel 1

Distribusi Frekuensi Karakteristik Responden

\begin{tabular}{ccc}
\hline Karakteristik & & \\
\hline Umur & $\mathbf{F}$ & $\%$ \\
\hline 15 & 13 & $6.3 \%$ \\
16 & 127 & $62.0 \%$ \\
17 & 53 & $25.9 \%$ \\
18 & 12 & $5.9 \%$ \\
\hline Jenis Kelamin & $\mathbf{F}$ & $\%$ \\
\hline Perempuan & 135 & $65.9 \%$ \\
Laki-Laki & 70 & $34.1 \%$
\end{tabular}

Berdasarkan tabel 1 menunjukan bahwa sebagian besar siswa berusia 16 tahun dengan persentase sebesar $62 \%$ dan berjenis kelamin perempuan sebesar $65.9 \%$.

\section{Tabel 2}

\section{Distribusi Frekuensi Kontrol Diri}

\begin{tabular}{lcc}
\hline \multicolumn{1}{c}{ Kontrol diri } & $\mathbf{F}$ & $\%$ \\
\hline Rendah $(x \leq 62)$ & 10 & 4.9 \\
\hline Sedang $(62<x \leq 93)$ & 148 & 72.2 \\
\hline Tinggi $(x>93)$ & 47 & 22.9 \\
\hline Total & 205 & 100 \\
\hline \multicolumn{2}{c}{ Berdasarkan tabel 2 menunjukan bahwa sebagian besar siswa SMA memiliki control diri sedang }
\end{tabular}
$(72.2 \%)$.

Indra Dwi Setiawan, Program Studi Kedokteran Fakultas Kedokteran Universitas Malahayati. Email: indradwisetiawan65@gmail.com Octa Reni Setiawati, Program Studi Psikologi Fakultas Kedokteran Universitas Malahayati. Email: ores.survie@gmail.com

Sri Maria Puji Lestari, Program Studi Kedokteran Fakultas Kedokteran Universitas Malahayati. Email: srimaria13pl@gmail.com 
Tabel 3

Distribus Frekuensi Perilaku Merokok

\begin{tabular}{lcc}
\hline \multicolumn{1}{c}{ Perilaku Merokok } & F & $\%$ \\
\hline Rendah $(x \leq 42)$ & 98 & 447.8 \\
\hline Sedang $(42<x \leq 63)$ & 107 & 52.2 \\
\hline Tinggi $(x>63)$ & 0 & 20 \\
\hline Total & 205 & 100 \\
\hline
\end{tabular}

Berdasarkan tabel di atas menunjukan bahwa sebagian besar siswa SMA menampilkan perilaku merokok dalam tingkat sedang $(52.2 \%)$

Tabel 4

Hasil Uji Korelasi Kontrol Diri dengan Perilaku Agresif

\begin{tabular}{ll}
\hline & Perilaku Merokok \\
\hline Kontrol Diri & $r=-.157^{*}$ \\
\hline${ }^{*} p<.05$ &
\end{tabular}

Berdasarkan hasil uji statistik Pearson, ditemukan hubungan yang signifikan antara control diri dengan perilaku merokok $(r(205)=-.157, p<.05)$. Kekuatan korelasi tergolong rendah dan bersifat negatif , artinya semakin tinggi kontrol diri maka semakin rendah perilaku merokok seseorang, sebaliknya semakin rendah kontrol diri seseorang maka akan semakin tinggi perilaku merokok seseorang.

PEMBAHASAN

\section{Kontrol Diri Siswa SMA}

Hasil penelitian menunjukkan rata-rata siswa memiliki kemampuan kontrol diri tingkat sedang. Hal ini bisa diartikan bahwa kemampuan kontrol diri siswa dapat menekan munculnya perilaku merokok. Kontrol diri dapat diartikan sebagai kemampuan pengendalian tingkah laku (Fadly, 2015). Pengendalian tingkah laku berarti melakukan pertimbangan terlebih dahulu sebelum memutuskan sesuatu atau mengambil tindakan tertentu. Dalam penelitian sebelumnya, ditemukan bahwa kontrol diri yang rendah menyebabkan remaja tidak mampu mengarahkan dan mengatur perilakunya, sehingga memperbesar kemungkinan munculnya perilaku negatif seperti merokok (Runtukahu, Sinolungan, \& Opod, 2015).

Berdasarkan hasil pengisian kuesioner kontrol diri, ditemukan bahwa mayoritas siswa mengisi kolom sangat setuju untuk kuesioner

Indra Dwi Setiawan, Program Studi Kedokteran Fakultas Kedokteran Universitas Malahayati. Email: indradwisetiawan65@gmail.com

Octa Reni Setiawati, Program Studi Psikologi Fakultas Kedokteran Universitas Malahayati. Email: ores.survie@gmail.com

Sri Maria Puji Lestari, Program Studi Kedokteran Fakultas Kedokteran Universitas Malahayati. Email: $\underline{\text { srimaria13pl@gmail.com }}$ 


\section{KONTROL DIRI DAN PERILAKU MEROKOK PADA SISWA SMA}

item 9 yaitu "Saya mudah terpengaruh terhadap ajakan orang lain meskipun saya tau hal tersebut salah". Bagi siswa hendaknya dapat berpendirian teguh dan tanamkan prinsip dalam diri agar tidak mudah terpengaruh pada hal-hal yang dapat merugikan diri sendiri dan orang lain.

\section{Perilaku Merokok Siswa SMA}

Hasil penelitian menunjukkan bahwa rata-rata siswa SMA memiliki perilaku merokok tingkat sedang. Hal ini bisa diartikan bahwa perilaku merokok siswa SMA Negeri 1 Trimurjo Kabupaten Lampung Tengah dalam kategori cukup. Perilaku merokok merupakan perilaku yang mengonsumsi produk tembakau yang dimaksudkan untuk dibakar, dihisap dan/atau dihirup termasuk rokok kretek, rokok putih, cerutu atau bentuk lainnya yang dihasilkan dari tanaman nicotina tabacum, nicotinarustica dan spesies lainnya atau sintetisnya yang asapnya mengandung nikotin dan tar, dengan atau tanpa bahan tambahan (Alamsyah \& Napianto, 2017). Perilaku merokok remaja yang tergolong sedang dapat berhubungan dengan proses pencarian jati diri pada remaja. Masa remaja adalah masa ketikaindividu mencari tahu siapa dirinya sebenarnya dan bagaimana menentukan masa depannya. Pencarian jati diri pada remaja melibatkan proses membandingkan dirinya dengan orang lain. Remaja yang cenderung mengikuti perilaku teman temannya atau berusaha sama dengan temantemannya dan kurang mampu mengontrol dirinya, akan memiliki intensi merokok yang tinggi (Hutapea \& Kustanti, 2017).

Erikson mengungkapkan remaja mulai merokok berkaitan dengan adanya krisis psikososial yang dialami pada masa perkembangannya yaitu masa ketika mereka sedang mencari jati dirinya. Dalam masa remaja ini, sering dilukiskan sebagai masa badai dan topan karena ketidaksesuaian antara perkembangan psikis dan sosial. Begitu pula pendapat Brigham bahwa perilaku merokok bagi remaja merupakan perilaku simbolisasi, yaitu simbol dari kematangan, kekuatan, kepemimpinan, dan daya tarik terhadap lawan jenis (Fadly, 2015)

Berdasarkan hasil pengisian kuesioner, ditemukan mayoritas siswa mengisi kolom setuju untuk kuesioner point 14 yaitu "Saya merokok ketika ditawari rokok oleh teman". Hal ini menunjukkan perilaku merokok siswa masih kuat dipengaruhi oleh faktor lingkungan. Bagi siswa hendaknya dapat menjaga diri dari lingkungan luar untuk mengontrol dirinya agar dapat terhindar dari perilaku negative seperti perilaku merokok.

Perilaku merokok pada sebagian orang umumnya dipicu oleh citra dalam diri tiap individu dan juga pergaulan dalam masyarakatnya. Remaja umumnya merokok karena sekedar ikut-ikutan orang yang lebih

Indra Dwi Setiawan, Program Studi Kedokteran Fakultas Kedokteran Universitas Malahayati. Email: indradwisetiawan65@gmail.com

Octa Reni Setiawati, Program Studi Psikologi Fakultas Kedokteran Universitas Malahayati. Email: ores.survie@gmail.com

Sri Maria Puji Lestari, Program Studi Kedokteran Fakultas Kedokteran Universitas Malahayati. Email: srimaria13pl@gmail.com 


\section{KONTROL DIRI DAN PERILAKU MEROKOK PADA SISWA SMA}

dewasa darinya. Kadang remaja ini merokok karena sekedar ingin mengikuti trend yang ada di sekitarnya (Fadly, 2015). Mangoenprasodjo (dalam Fadly, 2015) menambahkan bahwa gengsi, terlihat macho (keren), atau ingin dianggap dewasa, merupakan serangkaian alasan remaja merokok.

Hasil penelitian ini sesuai dengan penelitian yang sudah dilakukan sebelumnya oleh Amalia (2018), di dapatkan 39.05\% siswa dengan perilaku merokok tingkat rendah, $50.23 \%$ perilaku merokok tingkat sedang, serta $10,72 \%$ siswa dengan perilaku merokok tingkat tinggi. Hasil penelitian tersebut, menunjukkan bahwa rata-rata memiliki perilaku merokok tingkat sedang. Hal ini menggambarkan bahwa perilaku merokok masih banyak ditemukan dikalangan remaja.

\section{Hubungan Kontrol Diri Dengan Perilaku Merokok}

Hasil penelitian menunjukkan adanya hubungan negative bermakna antara kontrol diri dengan perilaku merokok. Perilaku merokok muncul dikarenakan rendahnya tingkat kontrol diri siswa, hal ini diakibatkan remaja yang tidak mampu untuk mengarahkan dan mengatur perilakunya sehingga perilaku negatif seperti perilaku merokok akan mudah memperaruhinya (Runtukahu, Sinolungan, \& Opo, 2015). Menurut Goldfield dan Merbaum (dalam Wulaningsih \& Hartini, 2015) kontrol diri merupakan suatu kemampuan untuk membimbing, menyusun, mengarahkan dan mengatur bentuk perilaku yang dapat membawa individu ke arah konsekuensi baik. Kontrol diri yang rendah dapat membuat munculnya perilaku negatif yang akan membuat krisis identitas, sehingga remaja memiliki kecenderungan berperilaku negatif (Fadly, 2015).

Dari pernyataan diatas maka dapat diambil kesimpulan bahwa kontrol diri sangat berpengaruh terhadap tindakan yang akan diambil. Seseorang yang tidak dapat mengendalikan atau mengontrol emosi dan perilakunya maka akan mengambil keputusan secara singkat untuk menentukan tindakannya oleh karena orang yang tidak bisa mengontrol emosi dan tindakannya akan mudah terpengaruh perilaku negatif seperti perilaku merokok. Segala tindakan yang telah diambil maka akan berpengaruh terhadap kelangsungan hidupnya. Semakin tinggi kemampuan kontrol diri sesorang maka semakin rendah perilaku merokok yang dia lakukan.

\section{SIMPULAN DAN SARAN}

Hasil penelitian menemukan bahwa sebagian besar siswa memiliki kemampuan control diri dan perilaku merokok tingkat sedang. Lebih lanjut, ditemukan adanya hubungan negative yang signifikan antara control diri dengan perilaku merokok pada siswa SMA. Hasil penelitian ini memberi implikasi bagi pihak

Indra Dwi Setiawan, Program Studi Kedokteran Fakultas Kedokteran Universitas Malahayati. Email: indradwisetiawan65@gmail.com Octa Reni Setiawati, Program Studi Psikologi Fakultas Kedokteran Universitas Malahayati. Email: ores.survie@gmail.com

Sri Maria Puji Lestari, Program Studi Kedokteran Fakultas Kedokteran Universitas Malahayati. Email: $\underline{\text { srimaria13pl@gmail.com }}$ 


\section{KONTROL DIRI DAN PERILAKU MEROKOK PADA SISWA SMA}

sekolah atau masyarakat diharapkan lebih memperhatikan permasalahan anak dan remaja terkait merokok. Selain itu, untuk penelitian selanjutnya, disarankan peneliti memilih waktu yang tepat, dan melibatkan guru sekolah dalam pengambilan data agar siswa dapat lebih kondusif saat penelitian berlangsung. Diharapkan peneliti selanjutnya dapat meneliti mengenai bagaimana cara mengatasi pengaruh negative dari perilaku merokok.

\section{DAFTAR PUSTAKA}

Alamsyah, A., \& Nopianto, N. (2017). Determinan Perilaku Merokok Pada Remaja. Jurnal Endurance: Kajian IImiah Problema Kesehatan, 2(1), 2530.

Ali, M, \& Asrori,M. (2014). Psikologi remaja: Perkembangan peserta didik.Jakarta: PT Bumi Aksara.

Amalia, M. N. (2018). Analisis Pengaruh Konsumsi Rokok Terhadap Produktivitas Tenaga Kerja Di Indonesia. Jurnal Pendidikan dan Ekonomi, 7(2), 162-174.

Fadly, R. T. (2015). Pengaruh kontrol diri terhadap perilaku merokok pada pengurus Pondok Pesantren Al-Amien Prenduan Sumenep-Madura (Doctoral dissertation, Universitas Islam Negeri Maulana Malik Ibrahim).

Faridah, F. (2017). Analisis Faktor-faktor Penyebab Perilaku Merokok Remaja di SMK "X" Surakarta. Jurnal Kesehatan Masyarakat (e-Journal), 3(3), 887-897.
Hernawily, H., \& Amperaningsih, Y. (2017). Hubungan Sikap Dan Norma Subyektif Dengan Niat Berhenti Merokok Pada Pegawai Laki-Laki Di Poltekkes Tanjungkarang. Jurnal IImiah Keperawatan Sai Betik, 11(2), 293-298.

Hutapea, H. T. Y., \& Kustanti, E. R. (2017). Hubungan antara persepsi terhadap peran ayah dengan intensi merokok pada siswa SMP Fransiskus Semarang. Empati, 6(1), 226-231. Isa, L., Lestari, H., \& Afa, J. R. (2017). Hubungan tipe kepribadian, peran orang tua dan saudara, peran teman sebaya, dan peran iklan rokok dengan periLaku merokok pada siswa Smp Negeri 9 Kendari tahun 2017. (Jurnal IImiah Mahasiswa Kesehatan Masyarakat), 2(7).

Maseda, D. R., Suba, B., \& Wongkar, D. (2013). Hubungan pengetahuan dan sikap tentang bahaya merokok dengan perilaku merokok pada remaja putra di SMA Negeri I Tompasobaru. Jurnal Keperawatan, 1(1).

Permatasari, N. P. $2016 . \quad H u b u n g a n$ Antara Kontrol Diri dan Perilaku Agresi Pada Remaja.Universitas Sanata Dharma: Yogyakarta.

Runtukahu, G. C., Sinolungan, J., \& Opod, H. (2015). Hubungan kontrol diri dengan perilaku merokok kalangan remaja di SMKN 1 Bitung. Jurnal e-Biomedik, 3(1).

Setyani, A. T., \& Sodik, M. A. (2018). Pengaruh Merokok Bagi Remaja Terhadap Perilaku dan Pergaulan Sehari-hari.

Indra Dwi Setiawan, Program Studi Kedokteran Fakultas Kedokteran Universitas Malahayati. Email: indradwisetiawan65@gmail.com

Octa Reni Setiawati, Program Studi Psikologi Fakultas Kedokteran Universitas Malahayati. Email: ores.survie@gmail.com

Sri Maria Puji Lestari, Program Studi Kedokteran Fakultas Kedokteran Universitas Malahayati. Email: srimaria13pl@gmail.com 
KONTROL DIRI DAN PERILAKU MEROKOK PADA SISWA SMA

Wijayanti, E., \& dewi, C. (2017). Faktor-faktor yang Berhubungan dengan Perilaku Merokok pada remaja kampong Bojong Eawalele, Jatimakmur, Bekasi. Global Medical \& health Communication, 2017, 5.3: 194-198.
Winengan, W. (2017). Implementasi Kebijakan Kawasan Tanpa Asap Rokok Di Kota Mataram. Jurnal IImu Administrasi: Media Pengembangan IImu dan Praktek Administrasi, 14(1), 1-16.

Wulaningsih, R., \& Hartini, N. (2015). Hubungan antara persepsi pola asuh orangtua dan kontrol diri remaja terhadap perilaku merokok di pondok pesantren. Jurnal Psikologi Klinis dan Kesehatan Mental, 4(2), 119-26.

Indra Dwi Setiawan, Program Studi Kedokteran Fakultas Kedokteran Universitas Malahayati. Email: indradwisetiawan65@gmail.com

Octa Reni Setiawati, Program Studi Psikologi Fakultas Kedokteran Universitas Malahayati. Email: ores.survie@gmail.com

Sri Maria Puji Lestari, Program Studi Kedokteran Fakultas Kedokteran Universitas Malahayati. Email: srimaria13pl@gmail.com 